\title{
AUDIT DOMAIN ACQUIRE AND IMPLEMENT DENGAN COBIT 4.1 PADA PT ERAJAYA SWASEMBADA TBK
}

\author{
Viany Utami Tjhin \\ School of Information System, BINUS University \\ Jln. K.H. Syahdan No. 9 Palmerah, Jakarta Barat 11480 \\ vtjhin@binus.edu
}

\begin{abstract}
The main priority aspect of information and communication technologies is given to control mechanisms, both internal and external in enterprises. It ensures that the reports and the decisions received and generated by the management will support their decision-making. The decisions have honesty and high integrity based on the results of the audit conducted on systems of information and communication technology. The objective of this research is to deliver audit reports of information systems for management and make recommendations on the audit findings in PT Erajaya Swasembada Tbk. Business processes studied included sales, purchasing, finance, and the warehouse. The system used was "Erajaya Live Application Server" and ERP (Enterprise Resource Planning)-based. This research used the domain of COBIT 4.1: Acquire and Implement. The domain included several sub-domains, which were:identify automated solutions (AI1), acquire and maintain application software (AI2), acquire and maintain technology infrastructure (AI3), enable operation and use (AI4), procure IT resources (AI5), manage changes (AI6), and install and accredit solutions and changes (AI7). Data were collected from interviewing IT Department, distributing questionnaires to respondents, and observing the business processes of this enterprise. Research obtained 57 audit findings on IT implementation. The results of process reference model formulation are 3 findings on AI1 subdomain, 5 findings on AI2 subdomain, 9 findings on AI3 subdomain, 6 findings on AI4 subdomain, 11 findings on AI5 subdomain, 13 findings pada AI6 subdomain, and 10 findings on AI7 subdomain. The level of maturity model of this domain, Acquire and Implement (AI), was found on level 3.
\end{abstract}

Keywords: audit, technology, information, COBIT 4.1, maturity model

\begin{abstract}
ABSTRAK
Dalam audit teknologi informasi, pritoritas utama diberikan kepada pengendalian internal dan eksternal. Hal ini dilakukan untuk menjamin pengambilan keputusan yang baik, berdasarkan hasil audit terhadap sistem organisasi. Objek penelitian adalah PT Erajaya Swasembada Tbk. Proses bisnis yang diteliti mencakup penjualan, pembelian, keuangan, dan gudang. Sistem yang diteliti merupakan sistem berbasis Enterprise Resource Planning (ERP). Hal yang diteliti menggunakan domain COBIT 4.1 yaitu Acquire and Implement (AI), terdiri dari identify automated solutions (AI1), acquire and maintain application software (AI2), acquire and maintain technology infrastructure (AI3), enable operation and use (AI4), procure IT resources (AI5), manage changes (AI6), and install and accredit solutions and changes (AI7). Metode pengumpulan data dilakukan dengan wawancara kepada departemen TI, menyebarkan kuesioner kepada responden perusahaan, serta melakukan observasi pada PT Erajaya Swasembada Tbk. Hasil penelitian diperoleh 57 temuan audit pada domain Acquire and Implement (AI) yaitu 3 temuan pada subdomain AI1, 5 temuan pada subdomain AI2, 9 temuan pada subdomain AI3, 6 temuan pada subdomain AI4, 11 temuan pada subdomain AI5, 13 temuan pada subdomain AI6, dan 10 temuan pada subdomain AI7. Hasil perumusan maturity model diketahui kematangan proses TI domain Acquire and Implement AI) pada tingkat 3.
\end{abstract}

Kata kunci: audit, teknologi, informasi, COBIT 4.1, maturity model 


\section{PENDAHULUAN}

Saat ini perusahaan sangat mengandalkan teknologi informasi dan komunikasi untuk menjalankan proses bisnisnya. Oleh karena itu, dunia bisnis perlu memahami aspek teknologi informasi dan komunikasi untuk dapat menerapkannya baik secara manajerial maupun teknikal pada proses bisnis dan kegiatan ekspansi Gondodiyoto (2007). Prioritas utama diberikan terhadap suatu mekanisme pengendalian - baik internal maupun eksternal — untuk memastikan bahwa laporan dan keputusan yang diterima dan dihasilkan oleh manajemen merupakan suatu pengambilan keputusan yang jujur dan mempunyai integritas tinggi. Laporan dan keputusan tersebut berdasarkan pada hasil audit yang dilakukan terhadap sistem berbasis teknologi informasi dan komunikasi organisasi bisnis yang bersangkutan. Hasil survei IBM (Singleton, 2011) yang dilakukan pada 2010 menunjukkan bahwa beberapa risiko TI ialah (i) keamanan TI/IT security (78\%), (ii) tidak berfungsinya hardware dan software (63\%), (iii) gangguan daya (50\%), dan (iv) keamanan fisikal (40\%).

Adapun tujuan audit sistem informasi ini adalah untuk mengukur tingkat kematangan implementasi teknologi informasi pada domain Acquire and Implement dengan menggunakan kerangka kerja COBIT 4.1. Salah satu standar penting dan efektif untuk diterapkan adalah Control Objectives for Information and Related Technology (COBIT). COBIT dikeluarkan oleh ISACA pada 1992 dan merupakan standar yang berorientasi pada proses, berfokus pada sasaran bisnis, dan merupakan alat manajerial dan teknikal untuk unit TI.

Rumusan masalah yang dirangkum dalam penelitian ini mencakup dua hal. Pertama, bagaimana kegiatan perolehan dan implementasi TI yang dilakukan oleh PT Erajaya Swasembada Tbk dalam hal sistem informasi. Kedua, bagaimana hasil rekomendasi yang bisa diberikan atas audit yang telah dilakukan pada PT PT Erajaya Swasembada Tbk terkait proses perolehan dan implementasi. Penelitian memuat landasan teori yang berhubungan dengan audit sistem informasi dan pengukuran tingkat kematangan pada implementasi teknologi informasi dengan memanfaatkan kerangka kerja COBIT 4.1.

\section{Tinjauan Pustaka}

\section{Audit Sistem Informasi}

Messier et al (2006) merumuskan definisi umum dari audit, yaitu: "suatu proses sistematis mendapatkan dan mengevaluasi bukti-bukti secara objektif sehubungan dengan asersi atas tindakan dan peristiwa ekonomi untuk memastikan tingkat kesesuaian antara asersi-asersi tersebut dan menetapkan kriteria serta mengkomunikasikan hasilnya kepada pihak-pihak yang berkepentingan." Sementara Arens et al (2005) menyatakan: "Auditing is the accumulation and evaluation of evidence about information to determine and report on the degree of correspondence between the information and established kriteria. Auditing should be done by a competent, independent person."

Lebih lanjut McLeod (2001) mendefinisikan sistem sebagai sekelompok elemen-elemen yang terintegrasi dengan maksud yang sama untuk mencapai suatu tujuan. Hall (2011) mendefinisikan sistem informasi sebagai sebuah rangkaian prosedur formal yang melaluinya data dikelompokkan, diproses menjadi informasi, dan didistribusikan kepada pemakai. Kemudian menurut Cangemi dan Singleton (2003): "Information sistems auditing is defined as any audit that encompass the review and evaluation of all aspects (or any portion) ofautomated information processing sistems, including related non-automated processes, and the interfaces between them." Lalu Hall (2011) menyatakan: "An IT Audit focuses on the computer-based aspects of an organization's information system. This audit includes assessing the proper implementation, operation, and control of computer resources. 
Because most modern information systems employ information technology, the IT audit is typically a significant component of all external (financial) and internal audits."

Lee (2014) berpendapat bahwa aspek manusia merupakan sumber risiko yang paling utama dan segala penyalahgunaan keputusan tergantung pada moralitas individu-individunya. Untuk itu, menurut Cascarino (2012), sistem pengendalian internal merupakan tindakan yang diambil oleh manajemen guna meningkatkan kemungkinan tercapainya tujuan dan sasaran yang telah ditetapkan.

\section{COBIT}

COBIT adalah sebuah framework tata kelola TI dan alat pendukung yang akan membantu para manajemen tingkat atas di bidang TI untuk menjembatani kesenjangan antara kebutuhan kontrol, isu teknis, dan risiko bisnis (ISACA, 2007). COBIT memungkinkan pengembangan kebijkan yang jelas dan dapat diimplementasikan untuk mengontrol seluruh aspek yang berkaitan dengan teknologi informasi sebuah organisasi. COBIT menekankan kepatuhan pada peraturan dan membantu organisasi untuk meningkatkan value dari sistem TI yang mereka bangun serta membantu penyelarasan antara tujuan teknologi informasi dan tujuan perusahaan. Selain itu COBIT juga dibuat sangat sederhana dengan tujuan agar sebuah framework IT Governance mudah dilaksanakan.

\section{Domain COBIT}

Menurut Hall (2011), "An IT Audit focuses on the computer-based aspects of an organization's information system. This audit includes assessing the proper implementation, operation, and control of computer resources. Because most modern information systems employ information technology, the IT audit is typically a significant component of all external (financial) and internal audits." COBIT 4.1 dalam dasar pengauditnya membagi perusahaan menjadi 4 domain utama, yaitu: Plan and Organize (PO), Acquire and Implement (AI), Deliver and Support (DS), dan Monitor and Evaluate (ME). Hal ini dapat terlihat pada Gambar 1.

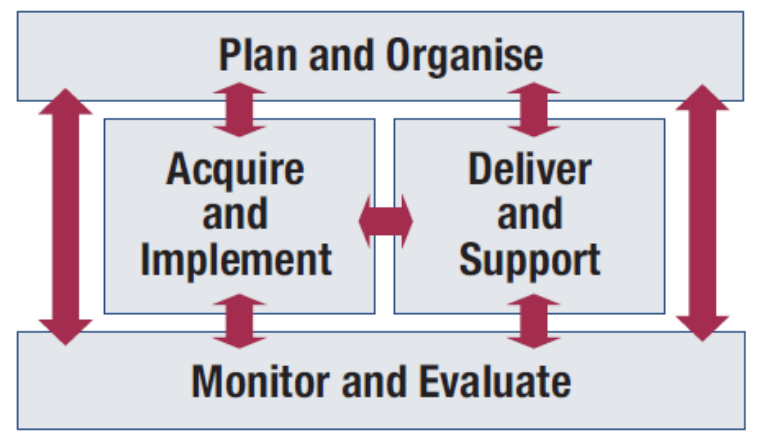

Gambar 1 Domain Utama COBIT 4.1

Sumber: ISACA, 2007

\section{Domain Acquire and Implement (AI) pada COBIT 4.1}

Adapun domain acquire and implement (AI) pada COBIT 4.1 membahas 7 sub domain sebagai berikut. AI1 - Identify automated solutions; kebutuhan untuk aplikasi baru memerlukan analisis sebelum adanya akuisisi atau penciptaan untuk memastikan bahwa kebutuhan bisnis puas dalam pendekatan yang efektif dan efisien. Proses ini meliputi definisi kebutuhan, pertimbangan sumber alternatif, review kelayakan teknologi dan ekonomi, pelaksanaan analisis risiko dan analisis biaya-manfaat, dan kesimpulan atas keputusan akhir untuk 'membuat' atau 'membeli'. Semua langkah 
memungkinkan organisasi untuk meminimalkan biaya untuk memperoleh dan menerapkan solusi sementara memastikan bahwa ada kemungkinan untuk mencapai tujuan. AI2 - Acquire and maintain application software; aplikasi yang dibuat tersedia sesuai dengan kebutuhan bisnis. Proses ini meliputi desain aplikasi, memasukkan kontrol ke aplikasi sesuai persyaratan keamanan, dan pengembangan konfigurasi sesuai dengan standar. Hal ini memungkinkan organisasi untuk benar mendukung operasi bisnis dengan aplikasi otomatis yang benar. AI3 - Acquire and maintain technology infrastructure; organisasi memiliki proses untuk pelaksanaan, akuisisi, dan upgrade dari infrastruktur teknologi. Ini membutuhkan pendekatan yang direncanakan untuk diakuisisi, pemeliharaan dan perlindungan infrastruktur sejalan dengan yang telah disepakati strategi teknologi dan penyediaan lingkungan pengembangan dan pengujian. Hal ini memastikan bahwa ada dukungan teknologi yang sedang berlangsung untuk aplikasi bisnis. AI4 - Enable operation and use; tersedianya pengetahuan tentang sistem baru. Proses ini membutuhkan pembuatan dokumentasi dan manual bagi pengguna dan bagian IT. Penyediaan pelatihan untuk memastikan penggunaan yang tepat dan pengoperasian aplikasi dan infrastruktur. AI5 - Procure IT resources; Sumber daya TI, termasuk SDM, hardware, software dan jasa, perlu diperoleh. Hal ini memerlukan definisi dan penegakan prosedur pengadaan, pemilihan vendor, setup pengaturan kontrak, dan akuisisi itu sendiri. Memastikan bahwa organisasi memiliki semua yang diperlukan sumber daya TI secara tepat waktu dan hemat biaya. AI6 - Manage changes; semua perubahan, termasuk perawatan darurat dan patch yang berkaitan dengan infrastruktur dan aplikasi dalam lingkungan produksi secara resmi dikelola dengan cara yang terkendali. Perubahan (termasuk parameter prosedur, proses, sistem dan layanan) akan dicatat, dinilai dan diberlakukan sebelum pelaksanaan dan ditinjau terhadap hasil yang direncanakan menyusul implementasi. AI7 Install and accredit solutions and changes; sistem baru perlu dibuat operasional setelah pembangunan selesai. Hal ini membutuhkan pengujian yang tepat dalam lingkungan khusus dengan data uji yang relevan, instruksi peluncuran dan migrasi, perencanaan rilis dan promosi yang sebenarnya untuk produksi, dan kajian pasca implementasi. Hal ini menjamin bahwa sistem operasional sejalan dengan yang disepakati.

\section{Tingkat Kematangan Implementasi TI pada COBIT 4.1}

Kerangka kerja COBIT 4.1 juga memasukkan hal seperti Maturity Model. Tingkat kematangan manajemen sistem dan teknologi informasi dapat dibagi menjadi enam level, yaitu: 0 Non-existent, 1 Initial/Ad Hoc, 2 Repeatable but Intuitive, 3 Defined, 4 Managed and Measurable, dan 5 Optimised.

\section{METODE}

Metode penelitian yang digunakan adalah metode COBIT 4.1 yang merupakan sebuah cara yang dapat ditempuh untuk dapat menganalisis, mengembangkan, mempublikasikan, dan mempromosikan suatu otorisasi. COBIT 4.1 ini berkonsentrasi pada pemanfaatan TI pada suatu perusahaan. Penelitian dilakukan dengan cara wawancara, penyebaran kuesioner, dan observasi. Wawancara dilakukan kepada pihak menejerial TI mengenai proses bisnis perusahaan serta macam pengendalian yang telah dilakukan di dalam organisasi. Penyebaran kuesioner dilakukan pada divisi TI, divisi Keuangan, divisi Penjualan, divisi Gudang, dan divisi Pembelian. Kuesioner dibagi menjadi 2 jenis yaitu kuesioner untuk TI dan kuesioner untuk non-TI. Observasi dilakukan secara langsung dengan menganalisis pengendalian catatan historis atau masa kini berupa print-out, menganalisis kondisi fisik, dan menganalisis proses atau aktivitas pengendalian atas input dan output yang dihasilkan. 


\section{HASIL DAN PEMBAHASAN}

Dalam melakukan kegiatan audit, penelitian memakai tahapan audit menurut Hunton et al (2004) yaitu: (i) perencanaan, (ii) penilaian resiko, (iii) persiapan program audit, (iv) mengumpulkan bukti audit, (v) membuat kesimpulan, (vi) menyampaikan opini audit, dan (vii) tindak lanjut.

Metode yang digunakan peneliti untuk menemukan solusi terbaik di dalam menganalisis kasus ini yaitu metode COBIT 4.1. Kerangka kerja ini adalah satu set best practies (framework) bagi pengelolaan teknologi informasi (IT management). COBIT bermanfaat bagi auditor karena merupakan teknik yang dapat membantu dalam identifikasi IT control issues. COBIT berguna bagi para pengguna TI karena memperoleh keyakinan atas kehandalan sistem aplikasi yang dipergunakan.

\section{RACI Chart}

Tahapan awal penggunaan metode COBIT, menurut ISACA (2007) para auditor perlu memetakan RACI terlebih dahulu. RACI merupakan singkatan dari Responsible, Accountable, Consulted dan Informed. RACI chart adalah matriks untuk seluruh aktivitas atau otorisasi keputusan yang harus diambil dalam suatu organisasi yang dikaitkan dengan seluruh pihak atau posisi yang terlibat. Tabel 1 menunjukkan RACI Chart pada domain AI.

Tabel 1 RACI Chart Domain Acquire and Implement (AI)

\begin{tabular}{|c|c|c|c|c|c|c|c|c|c|}
\hline AI1 & $\begin{array}{l}\text { Pres } \\
\text { Dir }\end{array}$ & Dir & GM & $\begin{array}{l}\text { Admin } \\
\text { Stok }\end{array}$ & Servis & Personalia & Finance & Promosi & TI \\
\hline $\begin{array}{l}\text { Define business functional \& technical } \\
\text { requirement }\end{array}$ & I & $\mathrm{C}$ & A & $\mathrm{R}$ & $\mathrm{R}$ & $\mathrm{R}$ & $\mathrm{R}$ & $\mathrm{R}$ & $\mathrm{R}$ \\
\hline $\begin{array}{l}\text { Identify document and analyze business } \\
\text { process risk }\end{array}$ & I & $\mathrm{C}$ & $\mathrm{A} / \mathrm{R}$ & & & & & & \\
\hline $\begin{array}{l}\text { Asses IT operational benefits for proposed } \\
\text { solutions }\end{array}$ & $\mathrm{C}$ & $\mathrm{C}$ & A & & & & & & $\mathrm{R}$ \\
\hline Asses business benefits of proposed solutions & $\mathrm{C}$ & $\mathrm{C}$ & A & $\mathrm{R}$ & $\mathrm{R}$ & & & $\mathrm{R}$ & \\
\hline Approved and sign off on solutions proposed & I & $\mathrm{C}$ & $\mathrm{A} / \mathrm{R}$ & & & & & & \\
\hline \multicolumn{10}{|l|}{ AI2 } \\
\hline $\begin{array}{l}\text { Translate business requirement into high level } \\
\text { design spec }\end{array}$ & $\mathrm{C}$ & $\mathrm{C}$ & A & $\mathrm{R}$ & $\mathrm{R}$ & I & I & $\mathrm{R}$ & I \\
\hline $\begin{array}{l}\text { Prepare detailed design \& technical software } \\
\text { app requirement }\end{array}$ & & I & $\mathrm{C}$ & & & & & & $\mathrm{A} / \mathrm{R}$ \\
\hline Track and manage application requirement & & & I & & & & & & $\mathrm{A} / \mathrm{R}$ \\
\hline $\begin{array}{l}\text { Develop a plan for maintenance of software } \\
\text { application }\end{array}$ & I & $\mathrm{C}$ & $\mathrm{C}$ & & & & & & $\mathrm{A} / \mathrm{R}$ \\
\hline \multicolumn{10}{|l|}{ AI3 } \\
\hline Define the acquisition procedure/process & $\mathrm{I}$ & $\mathrm{C}$ & A & & & & & & $\mathrm{R}$ \\
\hline $\begin{array}{l}\text { Discuss infrastructure requirement with } \\
\text { vendor }\end{array}$ & I & $\mathrm{C}$ & A & $\mathrm{R}$ & & & & & $\mathrm{R}$ \\
\hline $\begin{array}{l}\text { Define strategy and plan maintenance for } \\
\text { infrastructure }\end{array}$ & I & $\mathrm{C}$ & $\mathrm{C}$ & & & & & & $\mathrm{A} / \mathrm{R}$ \\
\hline Configure the infrastructure components & & $\mathrm{I}$ & I & & & & & & $\mathrm{A} / \mathrm{R}$ \\
\hline \multicolumn{10}{|l|}{ AI4 } \\
\hline Develop a strategy operationalise the solution & $\mathrm{C}$ & $\mathrm{C}$ & $\mathrm{R}$ & I & I & I & I & I & $\mathrm{R}$ \\
\hline Develop end user procedure manuals & & & & I & I & & I & I & $\mathrm{A} / \mathrm{R}$ \\
\hline $\begin{array}{l}\text { Develop technical support documentation for } \\
\text { operations }\end{array}$ & & & & I & I & & I & I & $\mathrm{A} / \mathrm{R}$ \\
\hline Develop and deliver training & & & & I & I & $\mathrm{C}$ & I & I & $\mathrm{A} / \mathrm{R}$ \\
\hline $\begin{array}{l}\text { Evaluate training results and enhance } \\
\text { documentation as required }\end{array}$ & & I & I & & & $\mathrm{C}$ & & & $\mathrm{A} / \mathrm{R}$ \\
\hline
\end{tabular}




\begin{tabular}{|c|c|c|c|c|c|c|c|c|c|}
\hline AI5 & & & & & & & & & \\
\hline Develop It procurement policies \& procedures & I & I & $\mathrm{C}$ & & & & & & $\mathrm{A} / \mathrm{R}$ \\
\hline $\begin{array}{l}\text { Establish/maintain a list of accredited } \\
\text { supplier }\end{array}$ & I & I & $\mathrm{I}$ & $\mathrm{A} / \mathrm{R}$ & & & & & $\mathrm{R}$ \\
\hline $\begin{array}{l}\text { Evaluate \& select suppliers through a request } \\
\text { for proposal process }\end{array}$ & I & I & I & $\mathrm{A} / \mathrm{R}$ & & & & & $\mathrm{R}$ \\
\hline $\begin{array}{l}\text { Develop contracts that protect the } \\
\text { organization interest }\end{array}$ & I & $\mathrm{C}$ & $\mathrm{C}$ & & & $\mathrm{C}$ & & & $\mathrm{A} / \mathrm{R}$ \\
\hline $\begin{array}{l}\text { Procure in compliance with establish } \\
\text { procedures }\end{array}$ & I & I & A & $\mathrm{R}$ & & & & & A \\
\hline \multicolumn{10}{|l|}{ AI6 } \\
\hline $\begin{array}{l}\text { Develop and implement a process to } \\
\text { consistency record }\end{array}$ & I & $\mathrm{C}$ & $\mathrm{C}$ & & & & & & $\mathrm{A} / \mathrm{R}$ \\
\hline $\begin{array}{l}\text { Asses impact and priorities changes based on } \\
\text { business needs }\end{array}$ & I & $\mathrm{C}$ & A & $\mathrm{R}$ & $\mathrm{R}$ & & $\mathrm{R}$ & $\mathrm{R}$ & $\mathrm{R}$ \\
\hline Authorize changes & I & I & $\mathrm{I}$ & $\mathrm{R}$ & $\mathrm{R}$ & $\mathrm{R}$ & $\mathrm{R}$ & $\mathrm{R}$ & $\mathrm{R}$ \\
\hline \multicolumn{10}{|l|}{ AI7 } \\
\hline Build and review implementation plans & I & I & $\mathrm{C}$ & & & & & & $\mathrm{A} / \mathrm{R}$ \\
\hline $\begin{array}{l}\text { Define and review test strategy and } \\
\text { methodology }\end{array}$ & I & I & I & $\mathrm{R}$ & $\mathrm{R}$ & & $\mathrm{R}$ & $\mathrm{R}$ & $\mathrm{R}$ \\
\hline $\begin{array}{l}\text { Perform system conversion and integration } \\
\text { test }\end{array}$ & I & I & $\mathrm{C}$ & & & & & & $\mathrm{A} / \mathrm{R}$ \\
\hline
\end{tabular}

Paparan hasil penelitian pada Tabel 2 menunjukkan jajaran manajemen di luar bidang sistem informasi manajemen menganggap bahwa dari 7 proses TI COBIT dalam domain AI, ditemukan 4 proses TI yang dinyatakan sangat penting dan 3 yang dinyatakan penting untuk diterapkan dalam pengelolaan TI. Pada proses TI ini tidak ada yang dianggap tidak penting untuk diterapkan.

Tabel 2 Penilaian Risiko Proses TI Acquire and Implement

\begin{tabular}{|c|c|c|c|c|c|c|}
\hline \multirow{2}{*}{\multicolumn{2}{|c|}{ Proses TI }} & \multicolumn{5}{|c|}{ Tingkat Kepentingan } \\
\hline & & 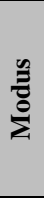 & 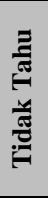 & 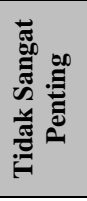 & 品 & 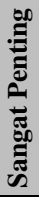 \\
\hline \multicolumn{7}{|c|}{ ACQUIRE AND IMPLEMENT (AI) } \\
\hline AI1 & Identify automated solutions. & 3 & & & $\sqrt{ }$ & \\
\hline AI2 & Acquire and maintain application software. & 3 & & & $\sqrt{ }$ & \\
\hline $\mathrm{AI} 3$ & Acquire and maintain technology infrastructure. & 3 & & & $\sqrt{ }$ & \\
\hline AI4 & Enable operation and use. & 4 & & & & $\sqrt{ }$ \\
\hline AI5 & Procure IT resources. & 4 & & & & $\sqrt{ }$ \\
\hline AI6 & Manage changes. & 4 & & & & $\sqrt{ }$ \\
\hline AI7 & Install and accredit solutions and changes. & 4 & & & & $\sqrt{ }$ \\
\hline \multicolumn{2}{|c|}{ Modus Penelitian Domain AI } & 4 & & & & $\sqrt{ }$ \\
\hline
\end{tabular}

Ekspektasi manajemen terhadap penanggung jawab proses TI AI. Penanggung jawab untuk masing-masing proses TI dan proses-proses TI COBIT apa saja yang akan ditangani oleh departemen TI PT Erajaya Swasembada, Tbk. (Tabel 3). Dari Tabel 3 digambarkan, bahwa penanganan proses AI dilakukan oleh pihak intern perusahaan, yang secara dominan ditangani oleh departemen TI beserta 3 proses yang ditangani bersama dengan departemen lain diluar departemen TI. 
Tabel 3 Penanggung Jawab Proses TI AI

\begin{tabular}{|c|c|c|c|c|c|c|}
\hline & Proses TI & 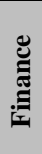 & 芯 & $\frac{\mathscr{E}}{\pi}$ & 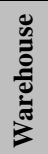 & E \\
\hline \multicolumn{7}{|c|}{ Acquire and Implement (AI) } \\
\hline AI1 & Identify automated solutions. & $\sqrt{ }$ & $\sqrt{ }$ & $\sqrt{ }$ & $\sqrt{ }$ & $\sqrt{ }$ \\
\hline $\mathrm{AI} 2$ & Acquire and maintain application software. & & & & & $\sqrt{ }$ \\
\hline $\mathrm{AI} 3$ & Acquire and maintain technology infrastructure. & & & & & $\sqrt{ }$ \\
\hline AI4 & Enable operation and use. & $\sqrt{ }$ & $\sqrt{ }$ & $\sqrt{ }$ & $\sqrt{ }$ & $\sqrt{ }$ \\
\hline AI5 & Procure IT resources. & & & & & $\sqrt{ }$ \\
\hline AI6 & Manage changes. & $\sqrt{ }$ & $\sqrt{ }$ & $\sqrt{ }$ & $\sqrt{ }$ & $\sqrt{ }$ \\
\hline AI7 & Install and accredit solutions and changes. & & & & & $\sqrt{ }$ \\
\hline
\end{tabular}

Berdasarkan hasil kuesioner yang telah dibagikan kepada divisi TI dan jajaran manajemen, diperoleh hasil perhitungan pada setiap domain adalah sebagai berikut.

\section{Identify automated solutions}

Tabel 4 Perhitungan Tingkat Kematangan pada Domain AI1

\begin{tabular}{cccccc}
\hline Level & Jumlah Skor & $\begin{array}{c}\text { Jumlah } \\
\text { Pertanyaan }\end{array}$ & Compliance & Normalisasi & Kontribusi \\
\hline 0 & 0 & 3 & 0 & 0 & 0 \\
1 & 3.66 & 4 & 0.915 & 0.216 & 0.216 \\
2 & 7.97 & 8 & 0.996 & 0.235 & 0.47 \\
3 & 3.96 & 12 & 0.33 & 0.078 & 0.234 \\
4 & 8.25 & 9 & 0.917 & 0.216 & 0.864 \\
5 & 11.88 & 11 & 1.08 & 0.255 & 1.275 \\
\hline \multicolumn{7}{r}{} & TOTAL & 4.238 & 1.00 & 3.059 \\
\hline
\end{tabular}

\section{Acquire and maintain application software}

Tabel 5 Perhitungan Tingkat Kematangan pada Domain AI2

\begin{tabular}{cccccc}
\hline Level & Jumlah Skor & $\begin{array}{c}\text { Jumlah } \\
\text { Pertanyaan }\end{array}$ & Compliance & Normalisasi & Kontribusi \\
\hline 0 & 0 & 4 & 0 & 0 & 0 \\
1 & 7 & 8 & 0.875 & 0.142 & 0.142 \\
2 & 7 & 5 & 1.4 & 0.227 & 0.454 \\
3 & 12.32 & 9 & 1.369 & 0.222 & 0.666 \\
4 & 14.94 & 11 & 1.358 & 0.22 & 0.88 \\
5 & 11.62 & 10 & 1.162 & 0.189 & 0.945 \\
\hline \multicolumn{7}{r}{} & TOTAL & 6.164 & 1.00 & 3.087 \\
\hline
\end{tabular}

\section{Acquire and maintain technology infrastructure}

Tabel 6 Perhitungan Tingkat Kematangan pada Domain AI3

\begin{tabular}{cccccc}
\hline Level & Jumlah Skor & $\begin{array}{c}\text { Jumlah } \\
\text { Pertanyaan }\end{array}$ & Compliance & Normalisasi & Kontribusi \\
\hline 0 & 0.99 & 6 & 0.165 & 0.046 & 0 \\
1 & 3.63 & 6 & 0.605 & 0.168 & 0.168 \\
2 & 4.3 & 7 & 0.614 & 0.171 & 0.342 \\
3 & 8.91 & 15 & 0.594 & 0.165 & 0.495 \\
4 & 8.25 & 11 & 0.75 & 0.209 & 0.836 \\
5 & 6.93 & 8 & 0.866 & 0.241 & 1.205 \\
\hline \multicolumn{7}{r}{} & TOTAL & 3.594 & 1.00 & 3.046 \\
\hline
\end{tabular}


Enable operation and use

Tabel 7 Perhitungan Tingkat Kematangan pada Domain AI4

\begin{tabular}{cccccc}
\hline Level & Jumlah Skor & $\begin{array}{c}\text { Jumlah } \\
\text { Pertanyaan }\end{array}$ & Compliance & Normaliasi & Kontribusi \\
\hline 0 & 0 & 2 & 0 & 0 & 0 \\
1 & 6.3 & 5 & 1.26 & 0.205 & 0.205 \\
2 & 9.93 & 9 & 1.103 & 0.18 & 0.36 \\
3 & 7.59 & 5 & 1.518 & 0.247 & 0.741 \\
4 & 15.19 & 15 & 1.013 & 0.165 & 0.66 \\
5 & 16.18 & 13 & 1.245 & 0.203 & 1.015 \\
\hline \multicolumn{7}{r}{ TOTAL } & & 6.139 & 1.00 & 2.981 \\
\hline
\end{tabular}

\section{Procure IT resources}

Tabel 8 Perhitungan Tingkat Kematangan pada Domain AI5

\begin{tabular}{cccccc}
\hline Level & Jumlah Skor & $\begin{array}{c}\text { Jumlah } \\
\text { Pertanyaan }\end{array}$ & Compliance & Normaliasi & Kontribusi \\
\hline 0 & 0 & 2 & 0 & 0 & 0 \\
1 & 5.64 & 5 & 1.128 & 0.162 & 0.162 \\
2 & 8.61 & 7 & 1.23 & 0.176 & 0.352 \\
3 & 10.23 & 5 & 2.046 & 0.294 & 0.882 \\
4 & 11.89 & 11 & 1.081 & 0.155 & 0.62 \\
5 & 14.86 & 10 & 1.486 & 0.213 & 1.065 \\
\hline \multicolumn{7}{r}{ TOTAL } & & 6.971 & 1 & 3.081 \\
\hline
\end{tabular}

\section{Manage Changes}

Tabel 9 Perhitungan Tingkat Kematangan pada Domain AI6

\begin{tabular}{cccccc}
\hline Level & Jumlah Skor & $\begin{array}{c}\text { Jumlah } \\
\text { Pertanyaan }\end{array}$ & Compliance & Normaliasi & Kontribusi \\
\hline 0 & 0 & 3 & 0 & 0 & 0 \\
1 & 6.3 & 5 & 1.26 & 0.198 & 0.198 \\
2 & 11.25 & 6 & 1.875 & 0.295 & 0.59 \\
3 & 12.87 & 13 & 0.99 & 0.156 & 0.468 \\
4 & 11.23 & 10 & 1.123 & 0.177 & 0.708 \\
5 & 12.22 & 11 & 1.111 & 0.175 & 0.875 \\
\hline \multicolumn{7}{c}{ TOTAL } & & 6.359 & 1.001 & 2.839 \\
\hline
\end{tabular}

Install and Accredit Solutions and Changes

Tabel 10 Perhitungan Tingkat Kematangan pada Domain AI7

\begin{tabular}{cccccc}
\hline Level & Jumlah Skor & $\begin{array}{c}\text { Jumlah } \\
\text { Pertanyaan }\end{array}$ & Compliance & Normaliasi & Kontribusi \\
\hline 0 & 0 & 3 & 0 & 0 & 0 \\
1 & 6.3 & 5 & 1.26 & 0.202 & 0.202 \\
2 & 10.92 & 6 & 1.82 & 0.292 & 0.584 \\
3 & 13.53 & 13 & 1.041 & 0.167 & 0.501 \\
4 & 11.23 & 10 & 1.123 & 0.18 & 0.72 \\
5 & 10.9 & 11 & 0.991 & 0.159 & 0.795 \\
\hline
\end{tabular}




\section{SIMPULAN}

Berdasarkan hasil penelitian yang telah dilakukan untuk domain Acquire and Implement (AI) pada COBIT 4.1 pada divisi IT di PT Erajaya Swasembada Tbk, disimpulkan sebagai berikut. Pertama, implementasi proses TI pada domain Acquire and Implement (AI) berada pada tingkat kematangan 3 - Defined, yaitu sebanyak 4 proses TI. Perusahaan mendapat 3 proses TI yang lain berada pada tingkat kematangan 2 - Repeatable but Intuitive. Kedua, Penerapan proses TI pada domain Acquire and Implement (AI) di departemen TI pada PT Erajaya Swasembada, Tbk dilakukan dengan mengidentifikasi solusi untuk otomatisasi, memelihara perangkat lunak aplikasi yang digunakan, memelihara infrastruktur teknologi informasi yang digunakan, mendukung operasi dan penggunaan TI, pengadaan sumber daya TI, mengelola perubahan, serta instalasi dan akreditasi solusi dan perubahan. Ketiga, dampak dari tingkat kematangan yang didapat pada masing-masing subdomain adalah (1) level 3 untuk Identify automated solutions (AI1) akan berdampak solusi yang digunakan belum dapat memenuhi semua kebutuhan proses bisnis perusahaan, dan harus mencari solusi alternative lainnya; (2) level 3 untuk Acquire and maintain application software (AI2) akan berdampak kurang efektif dan efisiennya pengendalian aplikasi dan tidak sesuai persyaratan keamanan, dan pengembangan konfigurasi sesuai dengan standar; (3) level 3 untuk Acquire and maintain technology infrastructure (AI3) akan berdampak kurangnya patuhnya terhadap kesepakatan strategi atas proses akuisisi dan upgrade dukungan teknologi yang sedang berlangsung untuk aplikasi bisnis; (4) level 2 untuk Enable Operation and Use (AI4) akan berdampak hasil yang didapat oleh organisasi menjadi kurang sesuai dengan perencanaan strategi dan tujuan organisasi yang telah dibuat, baik dari hasil pelatihan pengguna sistem dan pengoperasian aplikasi serta infrastruktur; (5) level 3 untuk Procure IT Resources (AI5) akan berdampak kurang tepatnya sumber daya Ti yang ditetapkan dan tidak efisiennya pengelolaan sumber daya TI dalam organisasi; (6) level 2 untuk Manage Changes (AI6) akan berdampak pada hasil yang didapat oleh organisasi menjadi kurang sesuai dengan perencanaan strategi perubahan dan tujuan organisasi yang telah dibuat; (7) level 2 untuk Install and Accredit solutions and changes (AI7) akan berdampak hasil yang diperoleh organisasi menjadi kurang sesuai dengan sistem operasional yang diharapkan.

Saran yang diberikan dalam penelitian ini adalah sebagai berikut. Pertama, sebaiknya perusahaan melakukan audit SI oleh pihak eksternal secara berkala sebab hal ini ditujukan untuk meningkatkan efektivitas dan efisiensi sistem informasi perusahaan. Kedua, dalam melakukan audit SI disarankan untuk memilih narasumber yang benar-benar menguasai uraian tugas (job description) yang dimilikinya sehingga informasi yang didapat oleh auditor menjadi lebih akurat. Ketiga, bersamasama dengan pihak manajemen membentuk kerangka umum untuk proses pemantauan dan evaluasi. Keempat, penjadwalan secara rutin proses pemantauan dan evaluasi (dalam setahun 1 sampai 2 kali proses evaluasi). Kelima, pembuatan sistem yang terintegasi untuk domain acquire and implement pada pengembangan sistem berikutnya.

\section{DAFTAR PUSTAKA}

Arens, A. A., Elder, R. J., \& Beasley, M. S. (2005). Auditing and Assurance Services: An Integrated Approach. Edisi 10. New Jersey: Prentice Hall.

Cangemi, P. M. \& Singleton, T. (2003). Managing The Audit Function. Edisi 3. New Jersey: John Willey \& Sons.

Cascarino, R. (2012). Auditor's Guide to IT Auditing. New Jersey: John Wiley \& Sons. 
Gondodiyoto, S. (2007). Audit Sistem Informasi: Pendekatan COBIT. Edisi Revisi. Jakarta: Mitra Wacana Media.

Hall, J. A. (2011). Information Technology Auditing and Assurance. United States: ACL Services.

Hunton, J. E., Bryant, S. M. \& Bagranoff, N. A. (2004). Core Concepts of Information Technology Auditing. International Edition. New Jersey: John Wiley and Sons.

ISACA. (2007). COBIT 4.1. USA: IT Governance Institute.

Lee, W. W. (2014). Why computer ethics matters to computer auditing. Journal of ISACA, 2. Diakses dari http://iethicssoc.org/articles/Why-Computer-Ethics-Matters-to-Computer Auditing_joa_Eng_0314.pdf

McLeod, R. Jr. (2001). Sistem Informasi Manajemen. Alih bahasa: H. Teguh. Jilid 1, Edisi Bahasa Indonesia. Jakarta: Prenhallindo.

Messier, W. F., Glover, S. M., \& Prawitt, D. F. (2006). Auditing \& Assurance Services: A Systematic Approach. Buku 1, Edisi 4. Jakarta: Salemba Empat.

Singleton, T. W. (2011). IT risks-present and future. Journal of ISACA, 4. Diakses dari http://www.isaca.org/journal/past-issues/2011/volume-4/pages/it-risks-present-andfuture.aspx. 